\title{
AN ANALYTICAL STUDY ON 'IMPACT OF ORGANIZATIONAL BEHAVIOR ON EMPLOYEES BEHAVIOR IN SELECTED EDUCATIONAL INSTITUTES OF KOTA CITY'
}

\author{
Sana Hafiz \\ Department of Commerce \& Management \\ Research Scholar, University of Kota, Rajasthan, India
}

\begin{abstract}
Organizational behavior looks at how workers influence each other and how an organization influences its workers. There are several factors that motivate workers These factors correlate directly to the workers' satisfaction. Educational institutions are regarded as organizations, which are a consciously and determinedly co-ordinated social units, comprising of two or more people. The organizations operate to implement their tasks and functions to achieve the desired goals and objectives. The members of the organizations are dedicated towards the performance of their job duties, which are geared towards achievement of a common goal or set of goals. They can involve leadership style, corporate culture or other workplace characteristics. Organizational behavior observes how staff members, workplace groups and corporate structures affect workers individually. The discipline incorporates concepts from communications, sociology, management and biology. The main purpose of this research paper is to study impact of organizational behaviour on employees in education sector. The effective implementation of organizational behaviour in educational institutes contributes to the enhancement of job performance, incurs job satisfaction and leads to achievement of desired goals and objectives. The main areas that have been taken into account are, nature and features of organizational behaviour, scope of organizational behaviour, need of organizational behaviour in education, contribution of educational fields to organizational behaviour, career development for organizational behaviour and challenges and opportunities for organizational behavior.
\end{abstract}

$\begin{array}{llr}\text { Keywords - Organizational } & \begin{array}{c}\text { behavior, } \\ \text { management, }\end{array} & \begin{array}{r}\text { Employee } \\ \text { Career }\end{array}\end{array}$ development, Job satisfaction

\section{INTRODUCTION}

Organisational behaviour refers to the behaviour of the individuals within the organizations, the reason being, organizations can operate efficiently, if the human resources are skilled and capable. Every organization needs employees who have superior performance. Performance is the result of work shown both quantitatively and qualitatively. Factors that may affect employee performance are an organizational commitment, organizational culture, and job satisfaction. Organisational behaviour is concerned with people's thoughts, feelings, emotions and actions in setting up a work. Understanding an individual behaviour is in itself is a challenge, but understanding group behaviour in an organisational environment is a monumental managerial task. The success of any educational institution depends upon the competence and capability of the management and the efficiency of the management depends upon the employees skills and needs and aspirations of individuals. It is an accepted fact that an organisation can progress only when its people are industrious. Organisational behaviour is a field of study that researches the influence of the individuals, group and structure upon the behaviour of the organisations. It covers three determinants of behaviour within the organisations, i.e. individuals, group and structure. It is an applied field, as it applies the knowledge acquired about individuals, and the effect of structure on behaviour, to make the organisations work more effectually. The performance of the organization is eventually dependent on the motivational levels of its human resources and enthusiasm and capability of the individuals to work pleasantly and co-operatively towards the achievement of common objectives. Organisational behaviour is an academic discipline concerned with defining, understanding, expecting and controlling human behaviour within an organisational environment . People, environment, technology and structure are the four main components of organizational behaviour. These components play a crucial part in influencing organizational behavior.

\section{LITERATURE REVIEW}

Organizational behaviour is the study of how the individuals behave both independently and within informal and formal groups. The performance of the institution is eventually dependent on the motivational levels of its human resources and enthusiasm and capability of the individuals to work pleasantly and co-operatively towards the achievement of common objectives. Organizational behaviour helps to understand different activities and conduct of the individuals, 
working within an institute. It also helps to stimulate them and they enrich their learning and understanding. People, environment, technology and structure are the four main components of organizational behaviour. These components play a crucial part in influencing organizational behavior

"K. Aswathappa; et al" (2002) studied human behaviour, attitudes and performance in organizations providing value added knowledge for individuals at all organizational levels. He further elaborated that Organizational behaviour can be regrarded as a systematic attempt to undertstand the behaviour of people in organization which they are an integral part. Organizational behaviour like organizational thoery, for this purpose, draws upon various other disciplines like psychology, sociology, anthropology, political science, economics and so on. The field of $\mathrm{OB}$ is both exciting and complex. OB has emerged as a distinct field of study. It is a distinct area of expertise with a common body of knowledge. OB is also an applied field. It applies the knowledge gained about individual groups and the effect of structure on behaviour in order to make organizations work more effectively. It represents only the behavioural approach to management. Hanna, V; Burns, N DBackhouse, and C J et al" (2000) Described explain the POS influence, the organisational behavioural a charting technique that can help a company determine if the concepts were identified for this study which is job different variables in the workplace are combining to produce an satisfaction, affective commitment and turnover intention. The environment that encourages positive workplace behavior. The purpose of this study is to identify the perceived organizational chart enables business managers to identify whether the support related to the job satisfaction, affective commitment organizational goals, performance measures and reward system, and turnover intention.

together with task and situation variables are all congruent or

mutually reinforcing. The research is still at an exploratory stage Meanwhile, according to Moorhead and Griffin (2013:73) and practical testing is continuing to examine the effectiveness of commitment is the attitude that reflects the extent to which an the chart. Some early case-study investigations inside a individual knows and tied to his organization. A highly manufacturing company are presented together with a synopsis of committed individual will likely see himself as a true member how the research will develop now the pilot study is complete. of the organization.Meanwhile, according to Kreitner and The author describe early results from research into the effect of Kinicki (2014:165) that organizational commitment reflects the organizational variables upon workplace behavior. In particular, degree to which a person recognizes an organization and is they discuss what influence organization and situational variables bound to its goals.It can be concluded that organizational have on performance. In organizations, groups of people are often commitment is the individual psychological state associated seen behaving in rather similar ways.

"Honingh, M., and Oort,et al. "(2009) compared teachers' organisational behaviour in publicly- and privately-funded schools in the Dutch Vocational Education and Training (VET) in publicly and privately funded schools (72 per cent and 43 per cent respectively) herein distributed self-report questionnaires were distributed to teachers measuring teachers' attitudes, sense of identification and perception of the school climate. The analyses show that teachers in publicly funded schools report a less curriculum-oriented attitude, a lower sense of identification, and perceive a less supportive school climate than teachers in privately funded schools. Funding did not have an effect on the extent to which teachers have a student-oriented attitude. In addition, the analyses show significant effects of teacher characteristics, the disciplinary sector, and affiliation characteristics on teachers' organisational behaviour. This study clearly indicates differences in teachers' organisational behaviour in publicly and privately funded schools. Contrary to common beliefs, the institutional context hardly influences the extent to which teachers have a student- with strong

beliefs, beliefs, and acceptance of organizational goalsand values, a strong willingness to work for the organization and the degree to which it wants to remain an organization member.

\section{NATURE AND FEATURES OF ORGANIZATIONAL BEHAVIOUR}

Organizational Behaviour is concerned with the understanding, prediction and control of human behaviour in organizations. It focuses on the individuals, the groups and the organization and also on their interactional relationships. It is the study and application of knowledge about how people act with organizations.It is a human tool for human benefit. It applies broadly to the behaviour of people in all types of organizations. Wherever organizations are, there is a need to understand organizational behaviour.

\section{Characteristics of $\mathbf{O B}$ :}

Organizational behaviour has emerged as a separate field of study. The nature it has acquired is identified as follows : 


\section{International Journal of Engineering Applied Sciences and Technology, 2019 \\ Vol. 4, Issue 2, ISSN No. 2455-2143, Pages 173-178 \\ Published Online June 2019 in IJEAST (http://www.ijeast.com)}

- $\quad$ is a part of general management.

- An Interdisciplinary Approach

- $\quad$ is an action-oriented and goal-directed discipline.

- $\quad$ is both a science and an art. The systematic knowledge about human behavior is a science. The application of behavioral knowledge and skills clearly leans towards being an art.

- A Humanistic and Optimistic Approach.

- OB seeks to fulfil both employees' needs and organizational objectives.

\section{SCOPE of OB:}

The scope of OB may be summed up in the words of S.P.Robbins as follows:

"OB is a field of study that investigates the impact that individuals, groups, and structure have on behaviour within organizations, for the purpose of applying such knowledge towards improving an organization's effectiveness".

The scope of OB involves three levels of behavior in organizations:

1. Individual Behavior

2. Group Behavior

3. Organization: Structure, Process and Application
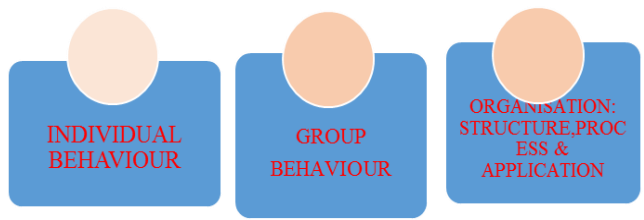

SCOPE OF OB

Fig. 1. Scope of OB

\section{KEY ELEMENTS IN OB}

The key elements in organizational behavior are people, structure technology and the environment in which the organizations operates. When people join together in an organization to accomplish an objective, some kind of structure is required. People also use technology to help get the job done, so there is an interaction of people, structure and the technology as shown in the given fig.1. In addition, these elements are influenced by the external environment, and they influence it.

People: People make up the internal social system of the organization. They consist of individuals and groups.

Structure: Structure defines the formal relationships of people in organizations.

Technology: Technology facilitates the physical and economic conditions within the working environment, which may smooth the operations of the individuals. Technology provides the resources with which people work and affects the tasks that they perform. The technology used has a significant influence in working relationships.
Environment: All organizations operate within an external environment. A single organization does not exist alone.

This study focuses on Organizational Behavior and its impact on Employees Behavior in several educational institutes of Kota City. Important dimensions such as Internal Communication System, Organizational Structure, Team Work, Power and Politics, Leadership, Administrative style, Implementation of Evaluation and Performance Appraisal are considered for analyzing Organizational Behavior in educational institutes. Dimensions such as Job satisfaction, Absenteeism, and resignation Rate are considered for analyzing educational institutes employees Behavior. The study includes several schools and coaching institutes of Kota City.

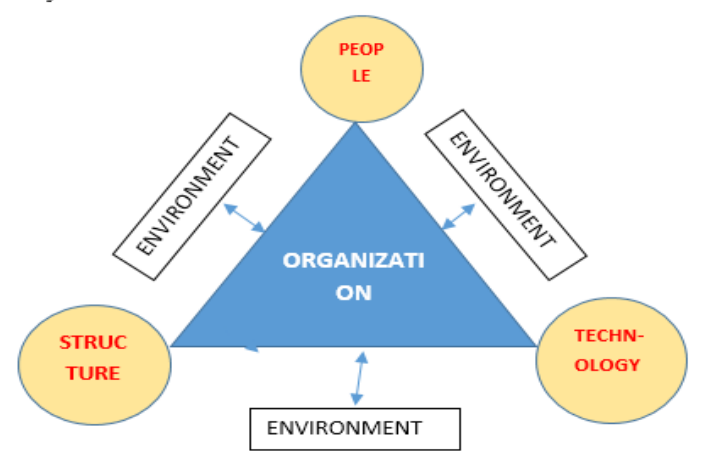

Fig. 2: Key elements in organizational behavior

\section{RESEARCH OBJECTIVES}

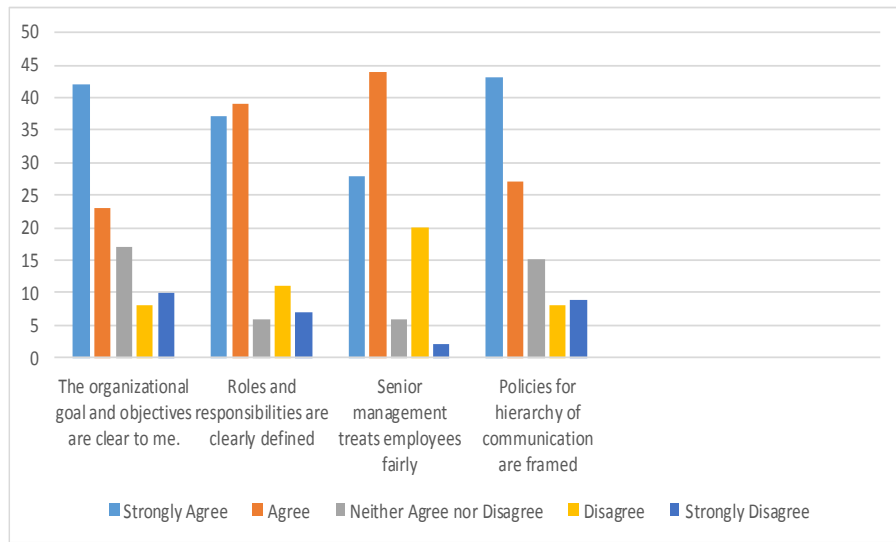

Research is basically aimed at determining ones view of related studies at every time. The researcher will therefore proceed to express and state those objectives which the study is expected to accomplish. They are as follows:

a. To study the effect of organizational behavior on size of organization.

b. To study the association between organizational behaviour and employees behavior. 
c. To study the association between leadership of organization and job satisfaction of employees.

d. To study the effect of Evaluation and appraisal of employees on employees satisfaction.

e. To study the effect of ethics and social responsibilities of organization on employees satisfaction.

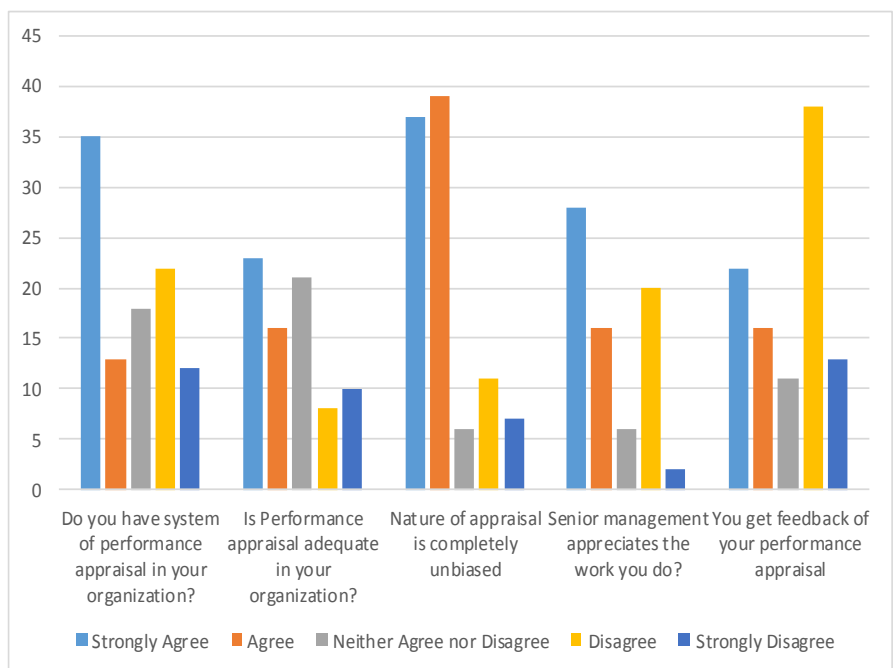

\section{RESEARCH METHODOLOGY}

To carry out the present research, survey method was employed by using stratified sampling technique. The target sample for this study was 100 respondents. The data of the study was collected from different Schools and educational institutes of Kota city through questionnaire. The questionnaire was developed using validated scales of the variables involved in the model. From 100 respondents in the organizations under study. The survey instrument consisted of 25 items questionnaire to be filled by the respondents for data analysis. All ratings were made using validated scales and on 5-Likert's Scale ( $1=$ Strongly Disagree and $5=$ Strongly Agree) except for management level where 5-Likert's Scale rated from (1=Rarely and $5=$ Very Often). In Demographics we took age, education level, marital status, job level, year of experience, nature of organization. The Cronbach's Alpha coefficient $(\alpha=0.914)$ was checked for reliability and validity of the questionnaire. The data so collected was subjected to Factor Analysis. the survey questionnaire also included a section to capture the general profile of respondents.

\section{DATA FINDINGS AND INTERPRETATION}

The study basically dealt with finding the organizational behavior effects on employee's behavior on the basis of 6 dimensions which are divided into 4 groups and finding the effect of same on the employees in education sector. Few of which are discussed below:

\section{a. ORGANIZATIONAL STRUCTURE:}

From the study it was found that maximum employees of the various educational institutes agreed to the rules and regulation of the organizations whether operating at larger or smaller scale. Except few employees who disagree with the fact that senior management treats employees fairly rest all the employees agree with it.

\section{b. IMPLEMENTATION OF EVALUATION AND APPRAISAL OF ORGANIZATION}

To understand the Implementation of Evaluation and appraisal of Organization five questions are asked to the respondents.

\section{LEADERSHIP OF ORGANIZATION}

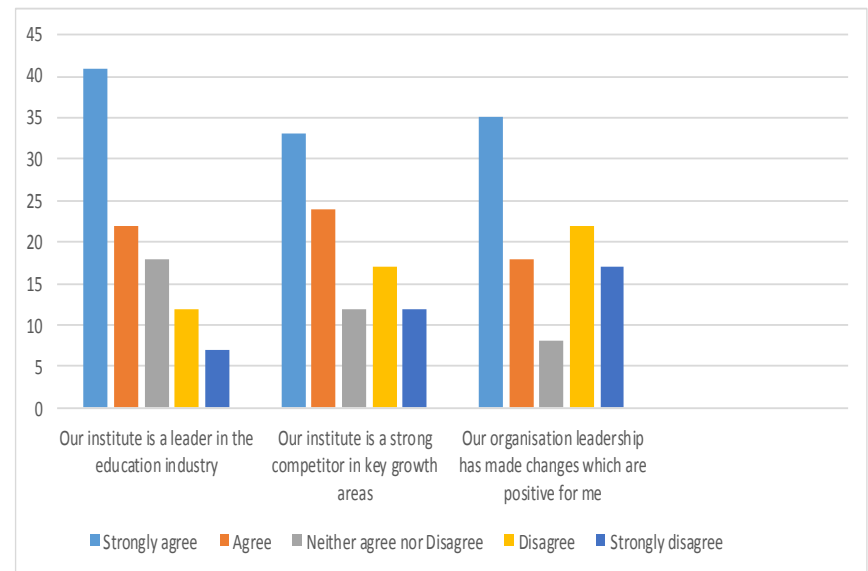

D - JOB SATISFACTION OF THE EMPLOYEES OF THE ORGANIZATION

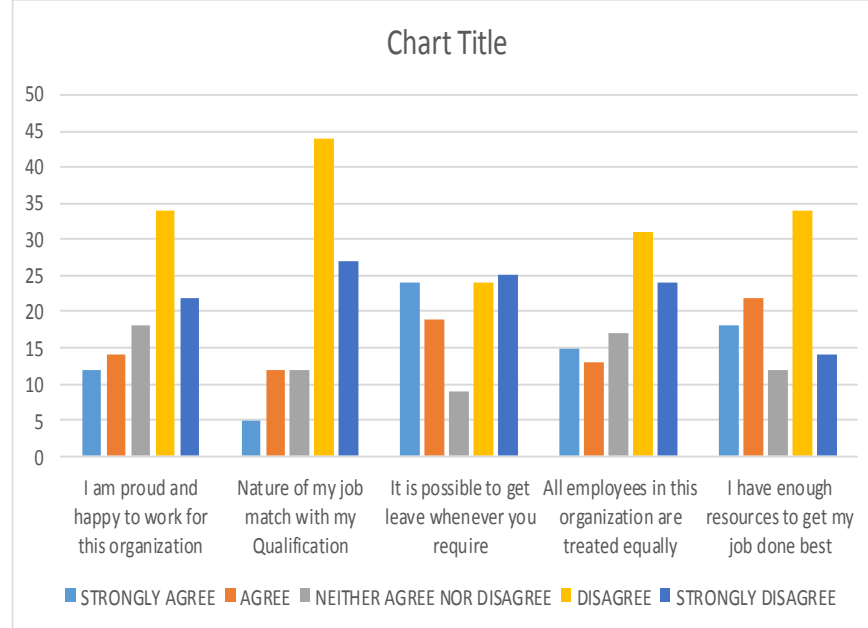




\section{E. ETHICS AND RESPONSIBILITY OF ORGANIZATION}

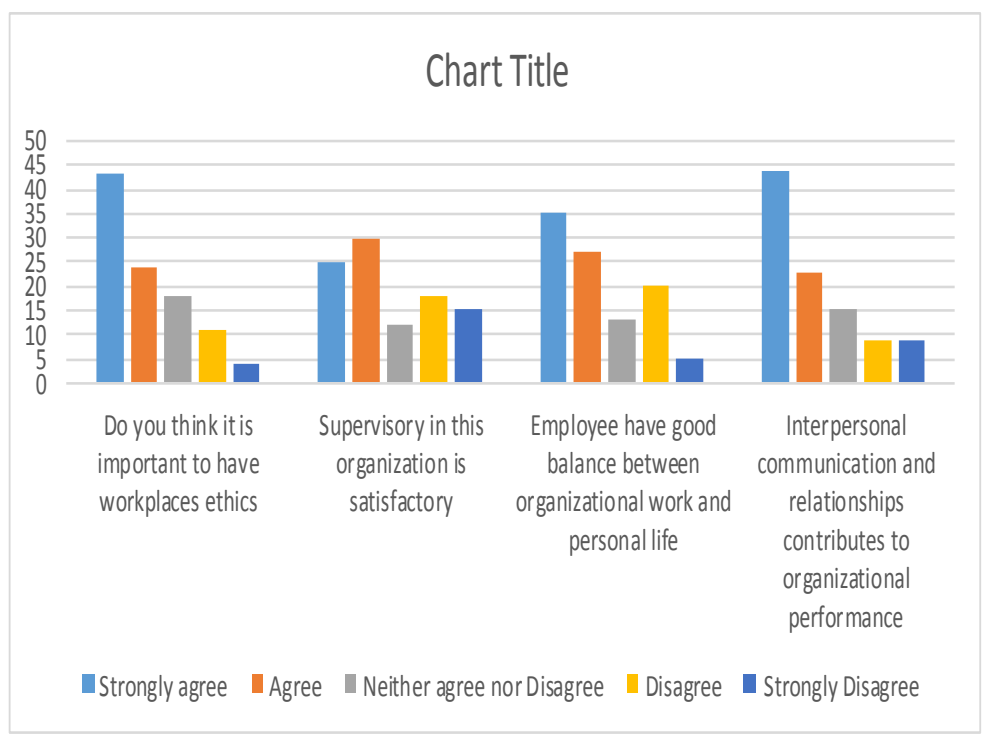

4. Talking about the Implementation of evaluation technique and appraisal system. It is suggested that it should be systematic so that the employees get equal opportunities to perform better. The senior management should give feedback to the employees so that they can improve themselves and get a chance to improve.

5. It is observed that the monetary benefits provided by the organizations should be satisfactory for the employees in the organization.

6. In case of absenteeism the employees should be given a compensatory leave in case they are required overtime in their job. They should be given flexibility in taking leave whenever they want.

7. The organizations should work hard for retaining their employees in their organizations so that the attrition rate is reduced and the employees are satisfied with their respective jobs and don't leave their job.

\section{SIGNIFICANCE OF THE STUDY}

The significance of this study is basically a definite scope which will help elicit the problems of organizational behavior in educational institutes. In addition, all the aforementioned and determined problems and solutions will be critically viewed to serve as possible recommendations to the educational institutes that may be willing to frame new strategies, rules, or appraisal systems and improve organizational behavior . It will forestall a better situation for the leader to select best type of leadership system.

Furthermore, the research will assist future researchers in finding possible solutions to the best leadership style after monitoring organizational behavior found in management and employees in different educational organizations.

\section{MAJOR FINDINGS \&RECOMMENDATIONS}

Based on the findings of the study the following recommendations on the dimensions of the organizational behaviour could be drawn:

1. It is been observed that the Organizational Structure of the organizations should provide the employees all information required as being the member of the organization. The roles and the responsibilities should be clearly defined to the employees of their respective organizations. Policies for the hierarchy of communication should be framed by the organizations.

2. As far as Internal environment of the organization is concerned organization should provide complete information in time to the employees of the organizations so that they can perform the job better and on time.

3. The employees in the organizations should be given equal work load so that there is no work pressure on few employees and the rest have no work to do.

\section{CONCLUSION}

The findings of the study highlighted that positive organizational behavior among the employees of educational institutes can be improved if the employees roles and the responsibilities are clearly defined to them of their respective organizations and policies for the hierarchy of communication should be framed by the organizations. Furthermore, the significance of nurturing employees organization based selfesteem is emphasized among the employees by providing positive organizational supports. It is concluded that evaluation technique and appraisal system should be systematic and properly implemented so that the employees get equal opportunities to perform better. The senior management should give feedback to the employees so that they can improve themselves and get a chance to improve. Organizations should work hard to keep Employees stress free and to reduce the attrition rate.

\section{REFERENCE}

[1] Karl Aquino and Douglas Scott (2003). Identity threat and antisocial behavior in organizations: The moderating effects of individual differences, aggressive modeling, and hierarchical status. Organizational Behavior and Human Decision Processes, 90,195-208

[2] Adhikari,and Atanu.(2009). "Factors Affecting Employee Attrition: A Multiple Regression Approach.” IUP Publications. IUP Journal of Management Research. Hyderabad. (Vol-8. pp38-43.)

[3] Cascio, W. F. (1986). Managing human resources: Productivity, quality of work life, profits. New York: McGrawHill.

[4] SURI SAPNA, Thesis, Submitted "The Impact Of Organizational Behaviour On Employees Behaviour In 
Pharmaceutical Companies In Selected Locations Of Maharashtra Viz; Mumbai, Pune, Nasik"

[4] Jackson, T. (2002). The management of people across cultures: Valuing people differently.Human Resource Management ( 41, 455-475.)

[5] Baron, Reuben A. (1986). Behavior in Organizations, Allyn and Bacon, Newton, MA.

[6] Wright, Thomas A. (2003). Positive Organizational behavior: an idea whose time has truly come. Journal of organizational Behavior, (24, 437-422)

[7] Lathans, Fred and Carolyn, Youssef M. (2007). Emerging Positive Organizational Behavior. Journal of Management, (33(3), 321-349)

[8] Kipling D. Williams. (2007). Ostracism. Annual Review of Psychology, (58, 425-452)

[9] Wright, Thomas A. (2003). Positive Organizational behavior: an idea whose time has truly come. Journal of organizational Behavior, (24, 437-422)

[10] Martin, Fabiola; Much nick, Marc. (2006) "The relationship between leadership practices and job satisfaction: A survey analysis of National Aeronautics and Space Administration employees at the Langley Research Center.

[11] Aswathapa K (2002) "organizational Behaviour" Himalaya Publications, Mumbai India .

[12] Saad Hanan Kattara,; Weheba, Dina; El-said, and Ahmed. Osman (2008). "The impact of employee behaviour on customers' service quality perceptions and overall satisfaction." SAGE PUBLICATIONS, INC. Tourism and Hospitality Research. US. Vol-8. pp- 309-323. 